مجلة أكاديمية شمال أوروبا المحكمة ـ الانمارك (الإصدار الأول) بتاريخ13/10/2018 $\mathrm{A}_{\mathrm{JNE}}{ }^{\mathrm{A}}$

\title{
استخدام المراكز الكهروحرارية المطورة \\ لإنتاج الطاقة الكهربائية ومياه التحلية
}

The use of thermoelectric centers developed

To produce electric power and desalinated water

اعداد

\section{Prepared by}

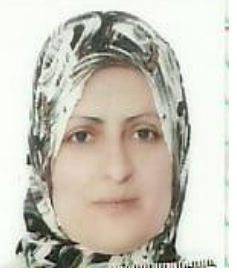

د. المهندسة. لمياء عبد الرضا عبد

Dr.Eng. Lammiaa Abdul Rudah abd كلية الإسراء الجامعة ـ بغداد ـ العراق

Al-Isra University College

Baghdad - Iraq

dr.Lamiaa@esraa.edu.iq

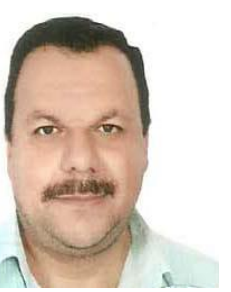

المهندس. مظفر كاظم كريدي Eng. Mudafar Kadum Krady مكتب مظفر للأستشارات الهندسية Mudafar Engineering Consulting Office Sultanate of Oman mudaferahmed@gmail.com 
تم في هذا البحث انشاء نموذج رياضي لدراسة اداء تطوير التصميم الأساسي لمراكز كهروحرارية مزدوجة ثنائية الضغط مخصصة لإنتاج الطاقة الكهربائية ومياه التحلية معا. وبصورة مقياس لفاعلية الحرارة والحفاظ على أدنى مستوى من التلوث للوسط المحيط وتم "استخدام التوفير في كمية الوقود المستهلكة في الكهربائية المستخدمة نتيجة للإنتاج المشترك للطاقة الكهربائية ومياه التحلية معا في التصميم المقترح مقارنة مع عملية الإنتاج المستقل للطاقة الكهربائية ومياه التحلية عن طريق محطة تجهيز ووحدة تحلية من نوع التناضح العكسي كما تم دراسة تأثير وحدة التحلية التبخيرية ذات التأثير المتعدد والوحدة التوربينية الغازية وكذلك الخواص الحرارية (الثرموديناميكية الأساسية لهذه الوحدة بالمقارنة مع التصميم الأساسي للمحطة البخارية .

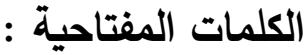
المراكز الكهروحرارية ـ الطاقة الكهربائية ـ المحطة البخارية ـ تحلية المياه ـ

\begin{abstract}
In this research, a mathematical model was created to study the performance of the development of basic design of dual electro thermal centers dedicated to the production of electric energy and desalinated water together. In the form of a measure of the effectiveness of the heat and maintaining the lowest level of pollution of the surrounding medium, for electricity and desalinated water together, in the proposed design compared to the independent production of electric power and desalinated water through a processing plant and reverse osmosis desalination unit .The effect of multi-effect evaporated desalination unit and the gas turbine unit, as well as the thermodynamic thermal properties of this unit, were compared with the basic design of the steam plant .
\end{abstract}

Key words:

Thermoelectric centers- Electric power- Steam station- Water Desalination. 
العديد من المناطق في العالم تعاني شحة في مصادر المياه الصالحة لأغراض الشرب

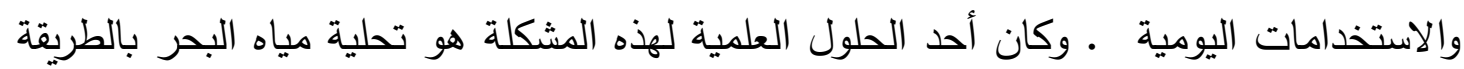
الحرارية [ 1 ] · وفي السنوات الاخيرة تميزت بارتفاع نسبة استعمال المراكز الكهروحرارية لتوليد

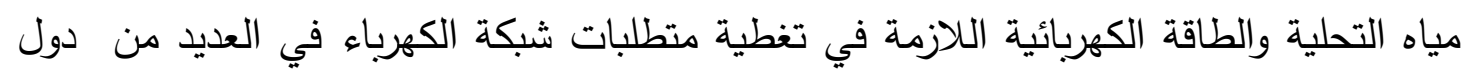

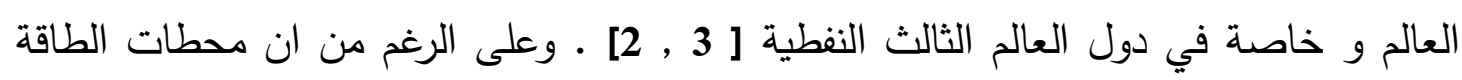

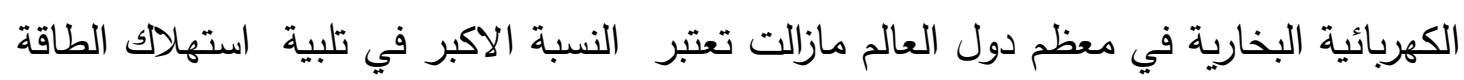

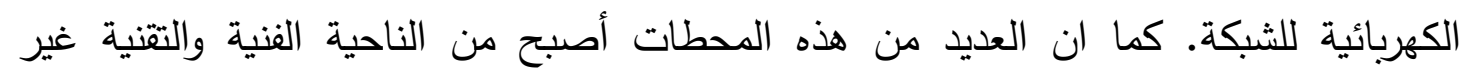
اقتصادي ضمن المقاييس العالمية للرصانة ومعدلات استهلاك الوقود لإنتاج الطاقة الكهبائية

و"تثير نتائج الدراسات الحديثة إلى الفاعلية الاقتصادية لاستخدام وحدات التحلية التبخيرية المتعددة التأثير في المراكز الكهروحرارية البخارية المخصصة لإنتاج الطاقة الكهربائية

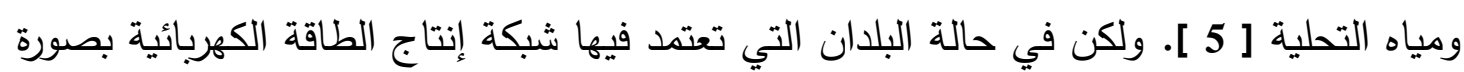
رئيسية على المحطات البخارية التكثيفية يصبح من الضروري التفكير في تجهيز الطاقة الحرارية

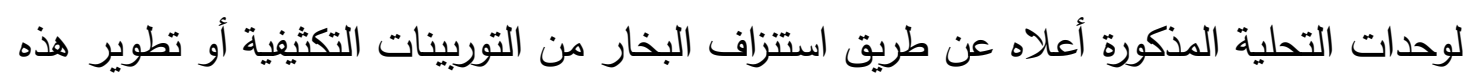

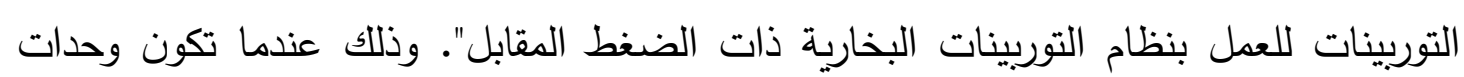

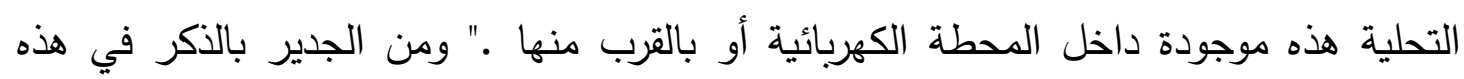

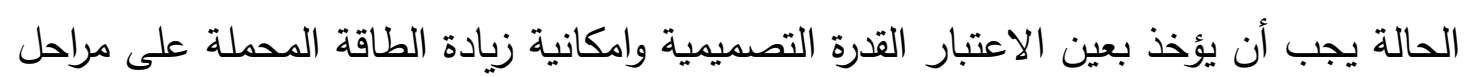

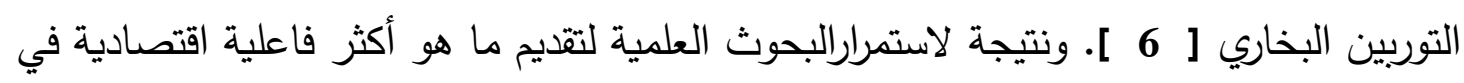

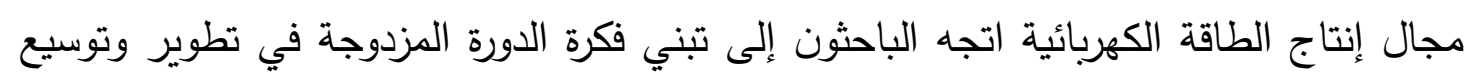
المحطات البخارية القديمة "[ 7 , 8 [ ].

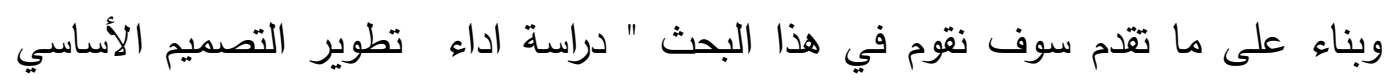

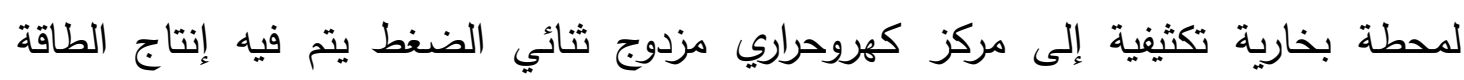
الكهربائية والطاقة الحرارية اللازمة لوحدات التحلية التبخيرية المتعددة التأثير". : 1.2 المحطة البخاريه مادة البحث

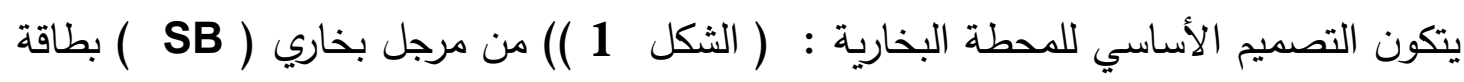
إنتاجية ( 320 ton/hr ) ووحدة تربينية بخارية تكثيفية ذات محور واحد وقدرة تصميمية 84.65 MW

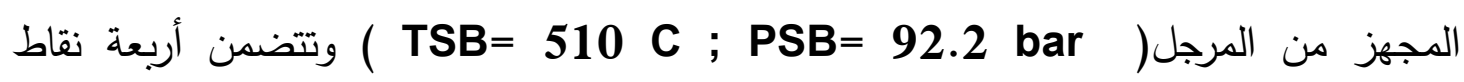


لاستتزاف البخار من اسطوانتي الضغط المرتفع والمنخف لغرض التسخين الاسترجاعي لمياه التغذية ( الجدول ( 1 ()).

الجدول ( 1 ) خواص البخار عند نقاط الاستنزاف المختلفة من التربينة البخارية .

\begin{tabular}{|l|c|c|c|c|c|c|}
\hline Point & 0 & 1 & D & 2 & 3 & C \\
\hline P , bar & $\mathbf{8 7 . 0}$ & $\mathbf{2 4 . 8 3}$ & $\mathbf{6 . 8 6}$ & 1.73 & $\mathbf{0 . 1 6 9}$ & $\mathbf{0 . 0 7}$ \\
\hline T , C & $\mathbf{5 0 5}$ & 336.2 & 303.7 & 115.2 & 56.2 & 38.8 \\
\hline
\end{tabular}

ان التصميم المقترح لتطوير التصميم الأساسي للمحطة البخارية قيد البحث مبين في الثكل ( 2 ). حيث تم تعديل تصميم المحطة البخارية إلى مركز كهروحراري مزدوج يتم فيه استغلال

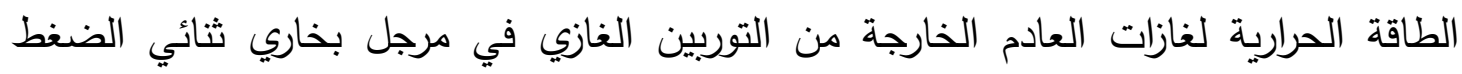

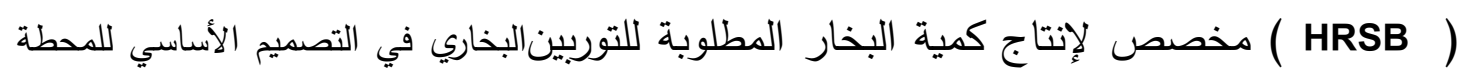

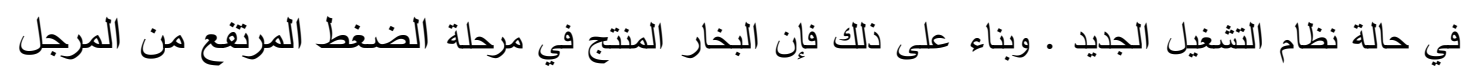

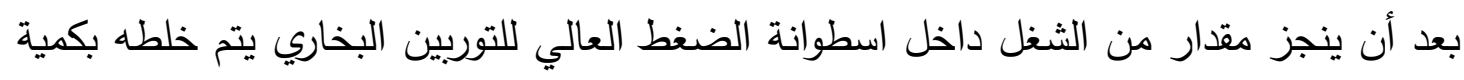

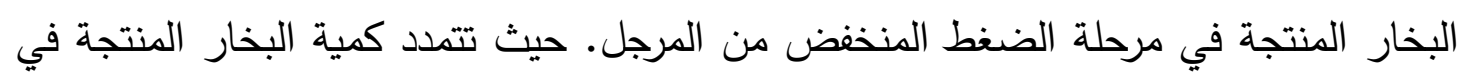

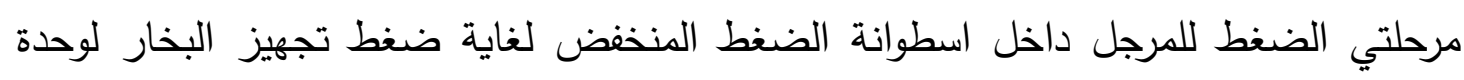
التحلية.

وقد تم في التصميم المقترح إلغاء المكثف والمبادلات الحرارية المخصصة للتشخين

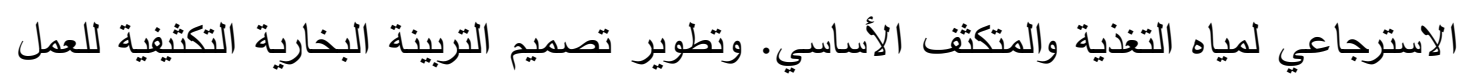
بنظام التوربينات البخارية الحرارية ذات الضغط المقابل ـ حيث تم إلغاء المراحل الثلاثة الأخيرة

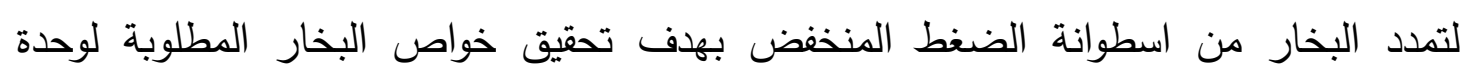

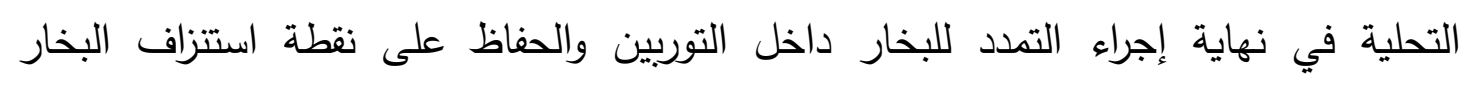

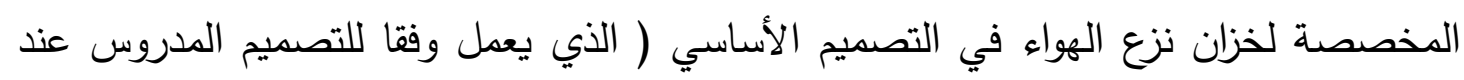

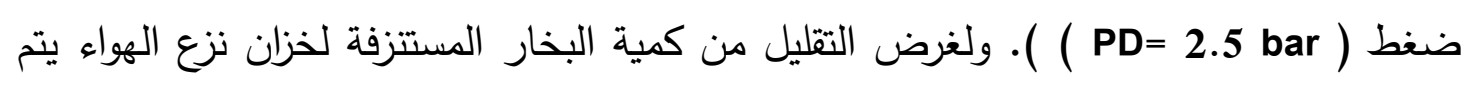

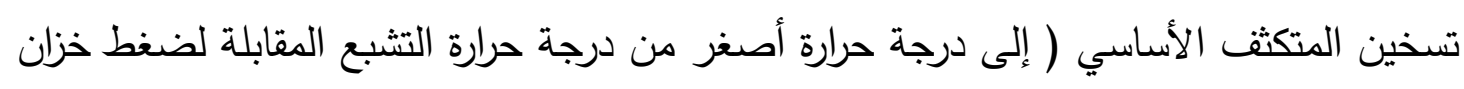

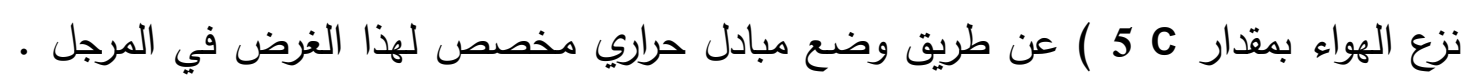

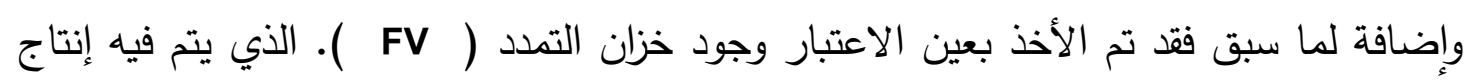
كمية من البخار الوميضي عن طريق كمية المياه المستنزفة من اسطوانتي مرحلتي المرجل.

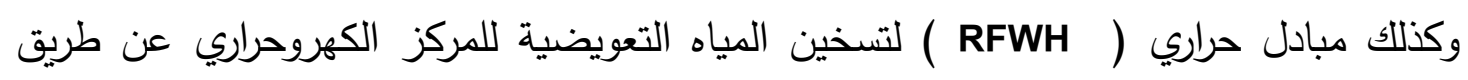

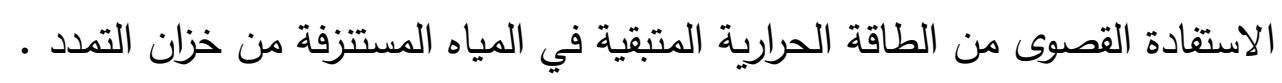




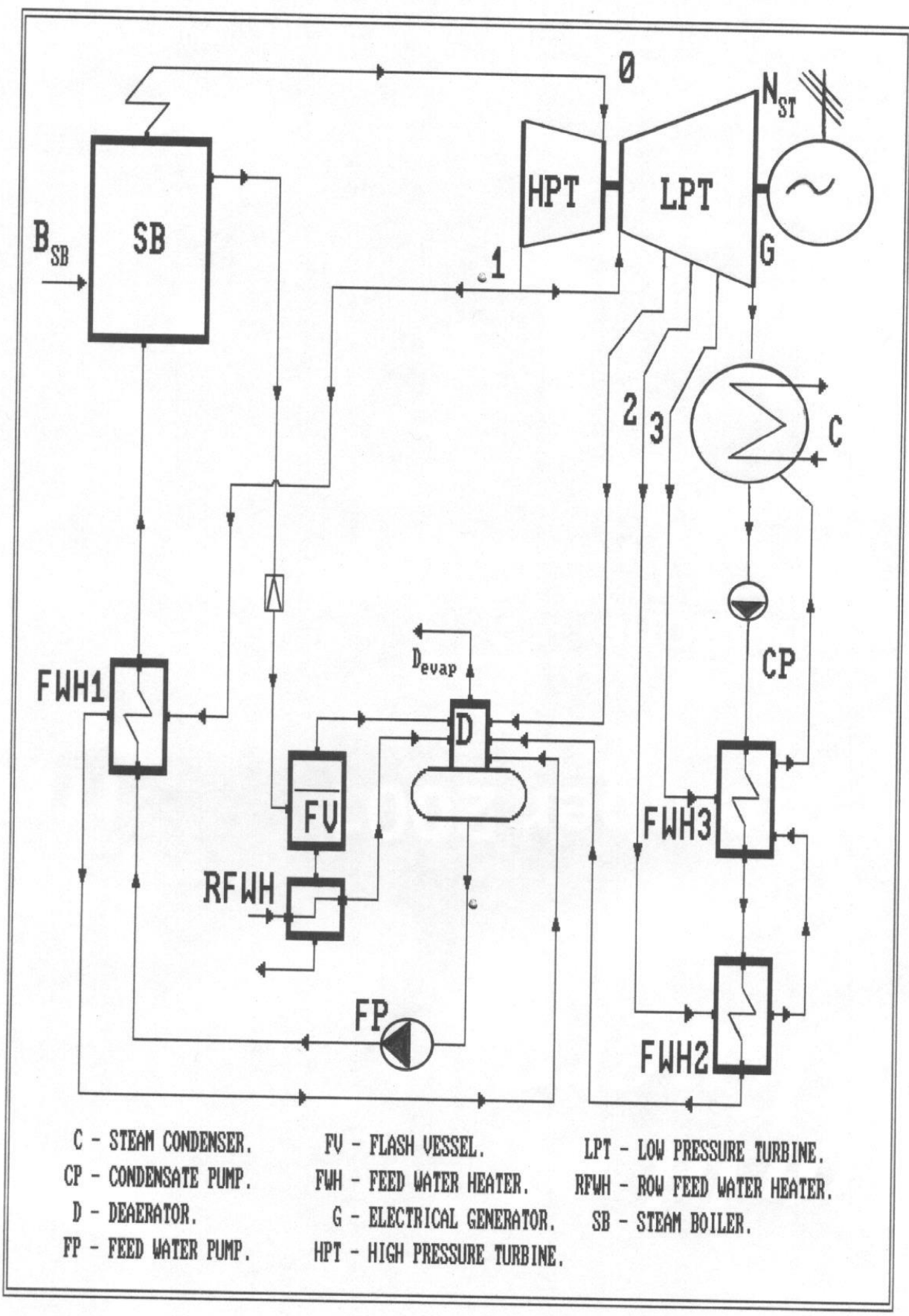

الثكل ( 1 )يوضح المحطة البخارية الاساسية.

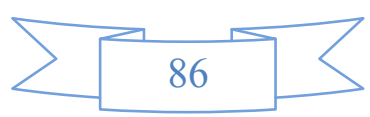




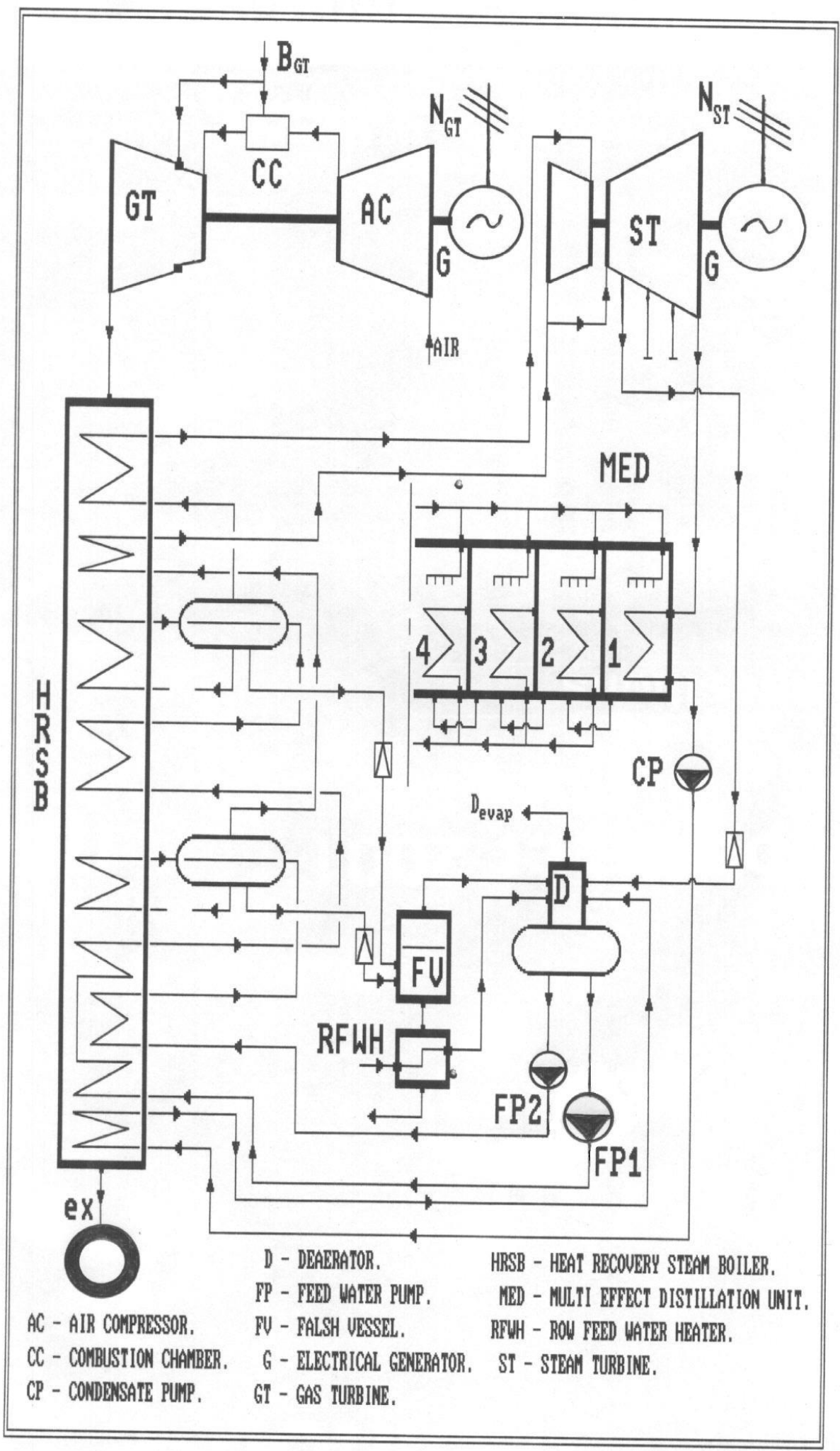

الثكل ( 2 ) التصميم المقترح للمركز الكهروحراري المزدوج .

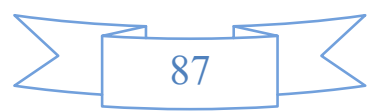


أما تصميم وحدة التحلية ( MED ) فيتكون من عدة مكثفات تبخيرية متتالية تشكل التأثيرات المتعددة لوحدة التحلية. ويتم تجهيز المحلول الملحي لهذه التأثيرات على التوازي بينما يستنزف المحلول الملحي المركز من تأثير إلى أخر بالتتابع (وفقا لتدرج الضغط داخل التأثيرات

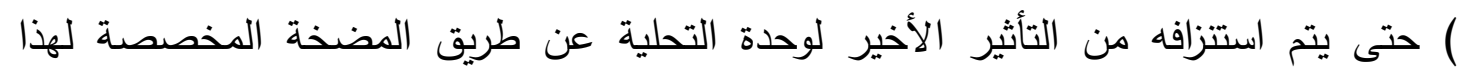

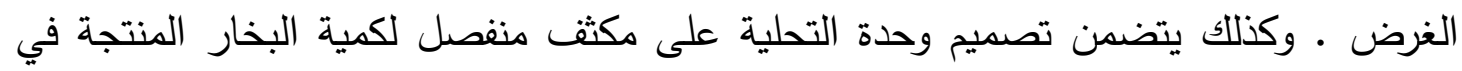
التأثير الأخير من وحدة التحلية . حيث يستخدم جزء من مياه التبريد لهذا المكثف في تجهيز كمية المحلول الملحي المطلوبة لوحدة التحلية . وتم في هذا البحث استخدام نوعين من التصاميم للوحدة التوربيني الغازي :

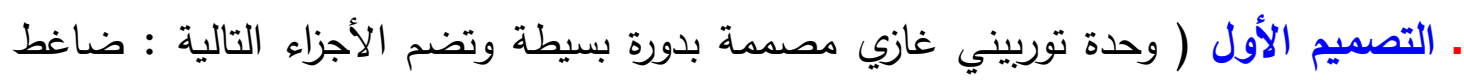

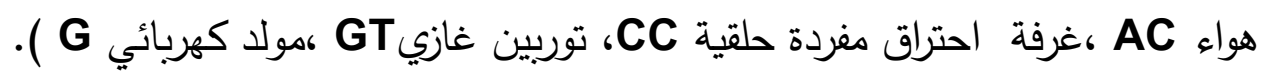

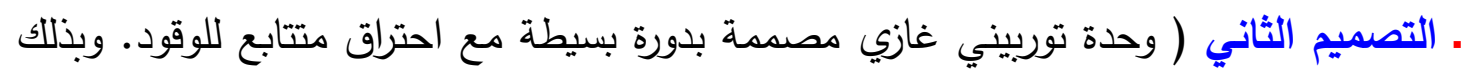

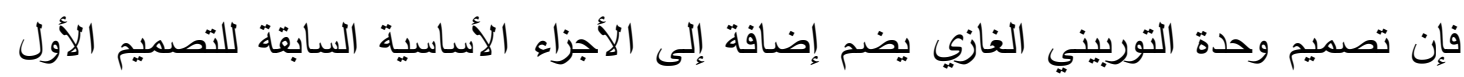
غرفة احتراق حلقية بعد المرحلة الأولى من التوبين الغازي ). 1.3 لدراسة الاداء الحراري للمراكز الكهروحرارية المزدوجة الثنائية الضغط يستلزم الأمر حساب

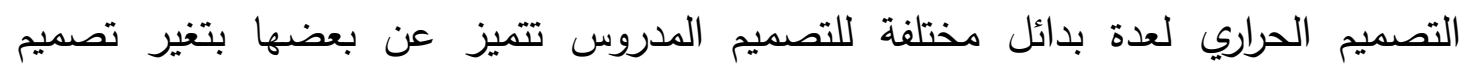

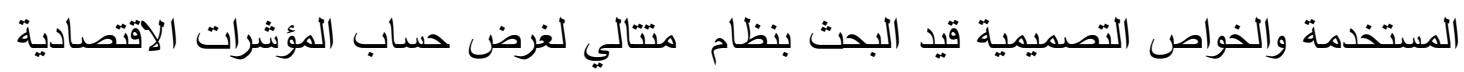

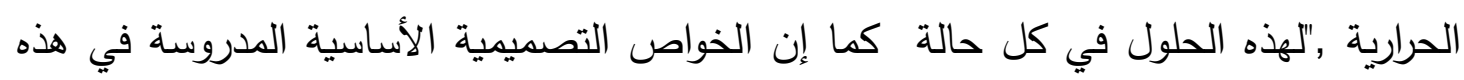

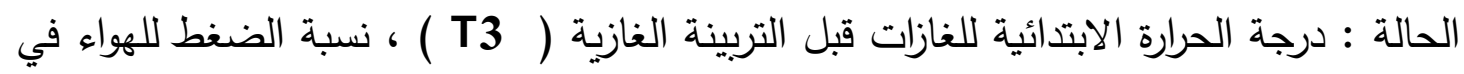

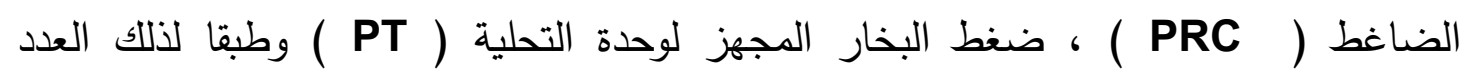

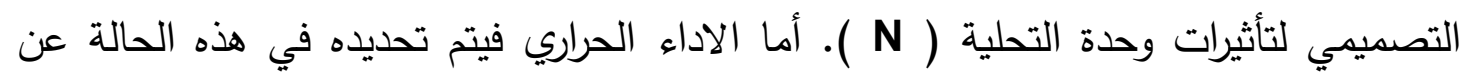
طريق مقدار التوفير في كمية الوقود المستهلكة في الثبكة الكهربائية نتيجة لعملية الإنتاج المشترك للطاقة الكهربائية ومياه التحلية مقارنة مع عملية الإنتاج المنفصل عن طرئ طرديق محطة مزدوجة بديلة لإنتاج الطاقة الكهربائية ووحدة تحلية من نوع التتاضح العكسي لإنتاج مئاه مياه

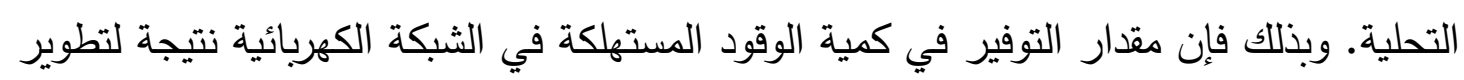

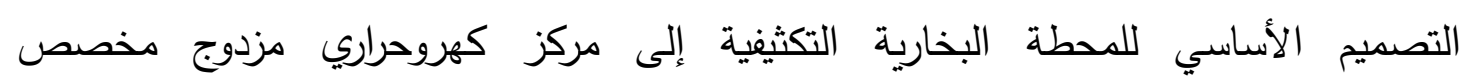
للإنتاج"الطاقة الكهربائية ومياه التحلية : 


$$
\begin{array}{r}
\text { DBST }=\frac{3600 *\left[\mathrm{NST}+\mathrm{NGT}-(\mathrm{NEST})_{\mathrm{O}}-\mathrm{NFP} 1-\mathrm{NFP} 2\right]}{\mathrm{Qcv}^{*} \mathrm{EST}}+(\mathrm{BSB})_{\mathbf{O}}+ \\
+\frac{3600 * \mathrm{DDW}^{*}[\mathrm{NRO}-\mathrm{NMED}]}{\mathrm{Qcv}^{*} \mathrm{EST}}-\mathrm{BGT} \quad(1) \quad \Rightarrow \max \\
: \text { حيث }
\end{array}
$$

الطاقة الكهبائية المنتجة (MGT, NGT التربينية الغازية على الترتيب. الطاقة الكهربائية المنتجة (MW) للوحدة التوربين البخاري في حالة نظام التشغيل الجديد

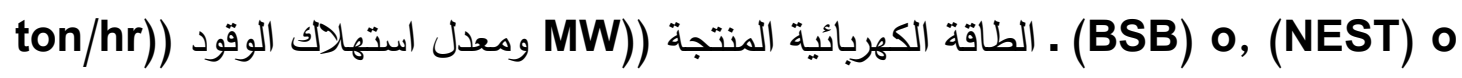
للمرجل في حالة التصميم الأساسي للمحطة على الترتيب.

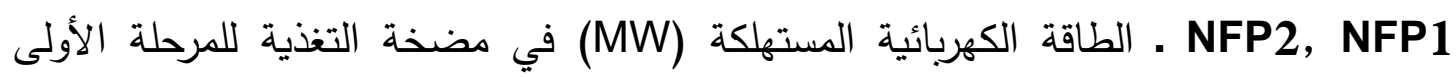

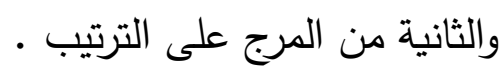
ـ كفاءة المحطة المزدوجة التعويضية لإنتاج الطاقة الكهربائية في الشبكة. EST Q Q القيمة الحرارية للوقود النوعي (kST/kg

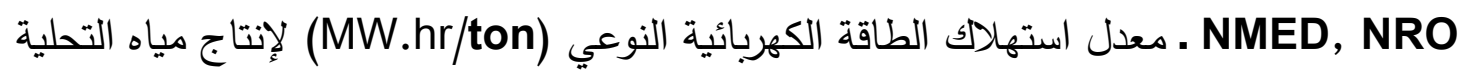
في وحدة التحلية من نوع التتاضح العكسي والوحدة التبخيرية المتعددة التأثير على الترتيب .

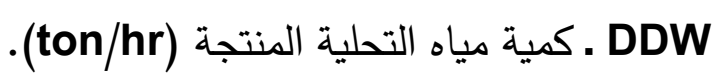
و "بذللك فإن البديل المناسب هو الذي يعطي أقصى قيمة للمعادلة ( 1 ) ( أي البديل الذي عنده

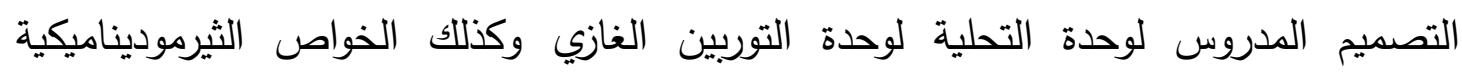

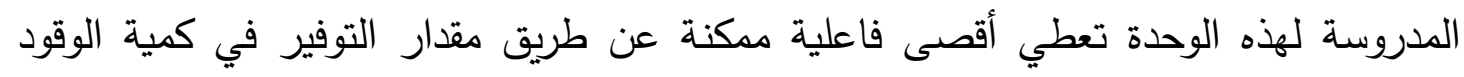
المستهلكة لإنتاج الطاقة الكهربائية ومياه التحلية. ومن الجدير بالذكر في عملية بناء النموذج الرياضي الخاص بحساب التصميم الحراري

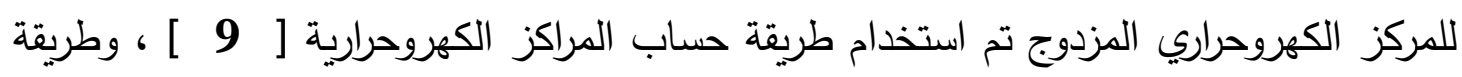

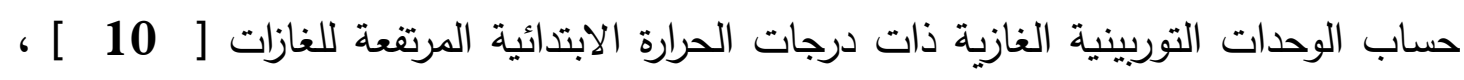
وطريقة حساب المراجل البخارية المخصصة لاستغلال المصادر الثانوية للطاقة [ 11 ل 10 ] ، 10 وطريقة حساب وحدات التحلية التبخيرية المتعددة التأثير [ 12 ]. إضافة إلى ما تقدم تم تعديل التيل

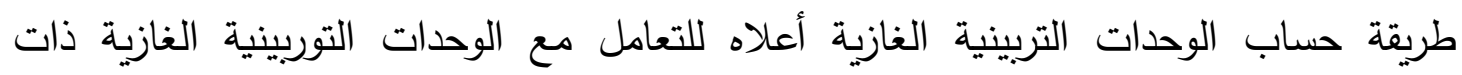

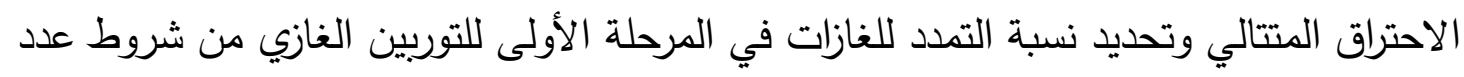


المراحل لهذا التوربين والتوزيع المتساوي لـقدار الهبوط في طاقة الغازات "على هذه المراحل ]

\section{4}

تم دراسة تأثير تصميم وحدة التوربين الغازي والخواص التصميمية الأساسية السابقة أعلاه على مقياس" الاداء الاقتصادي للتصميم قيد البحث للمركز الكهروحرارية المزدوج ( مقدار التوفير في كمية الوقود المستهلكة في الشبكة الكهربائية ومياه التحلية ). ويبين الثكل ( 3 ( 3 )

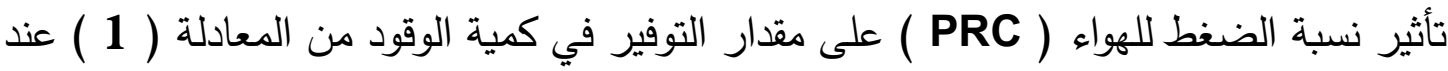

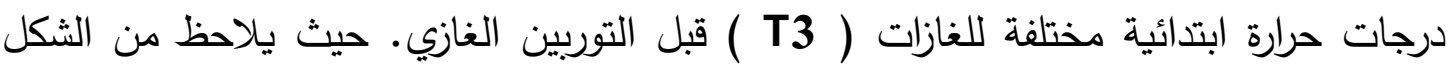
ارتفاع مقدار التوفير في كمية الوقود المستهلكة مع زيادة نسبة الضغط ـ ـوالسبب في ذللك يمكن

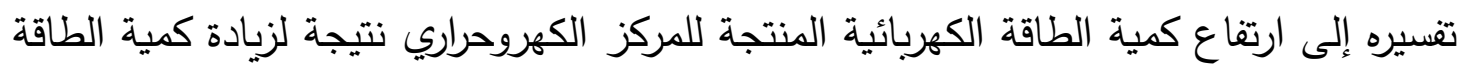
الكهبائية المنتجة لوحدة التوربين الغازي NGT بمقدار اكبر من الانخفاض في كمية الطاقة الكهربائية المنتجة لوحدة التوربين الغازي NST N ( الثكل ( 4 )). ومن ثم ارتفاع كفاءة المركز

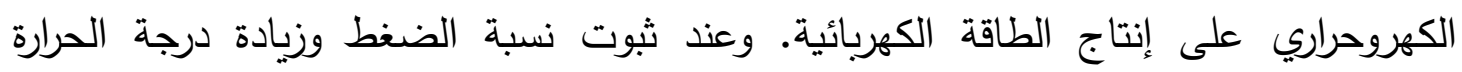
الابتدائية للغازات قبل التربينية الغازية يلاحظ من الثكل ( 4 ) ارتفاع مقدار التوفير في كمية

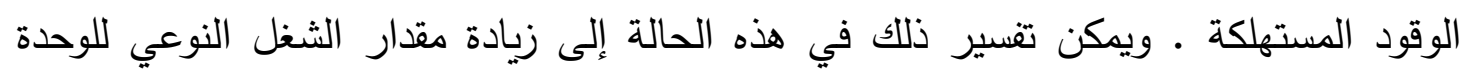

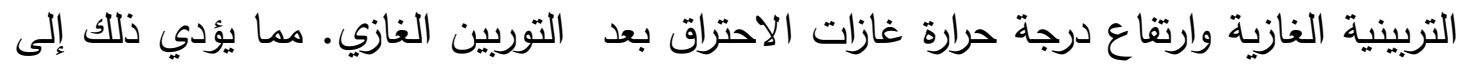
انخفاض كمية غازات الاحتراق المطلوبة في المرجل لإنتاج كمية البخار اللازمة للوحدة التربينية

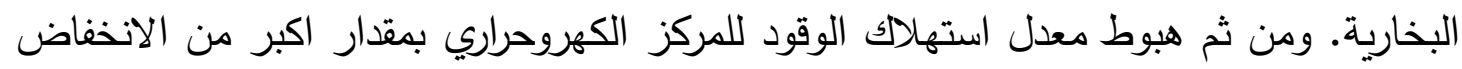

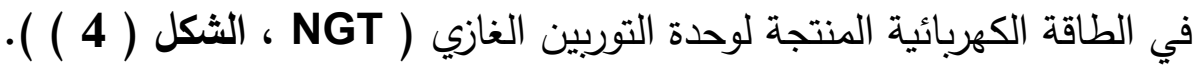
كما يبين الثكل ( 3 ) ارتقاع مقدار التوفير في كمية الوقود المستهلكة في حالة استخدام التصميم المدروس الثاني لوحدة التوبين الغازي في المحطات والمراكز الكهروحرارية المزدوجة الكارية

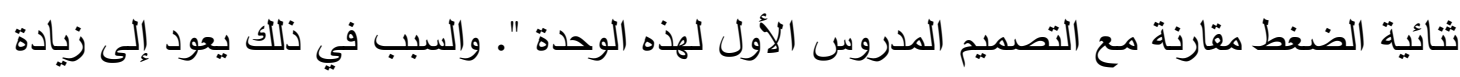
كمية الطاقة الكهربائية المنتجة لوحدة التوربين الغازي ( NST ، الثكل ( 4 ( ) ) ) وارتفاع مقدار

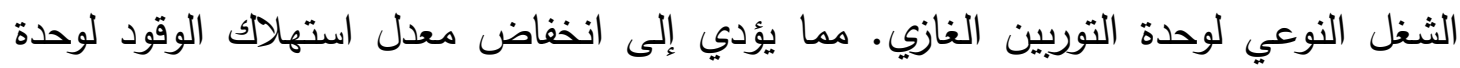

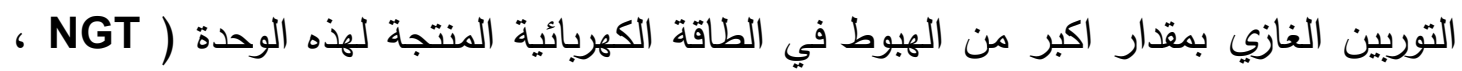
الثكل ( 4 ) ). وكذلك يلاحظ من الثكل ( 3 ) هناللك قطع في نهاية المنحنيات في حالة التصميم الددروس الأول لوحدة التوربين الغازي. وسبب ذلك يمكن تفسيره إلى عدم توافق شروط

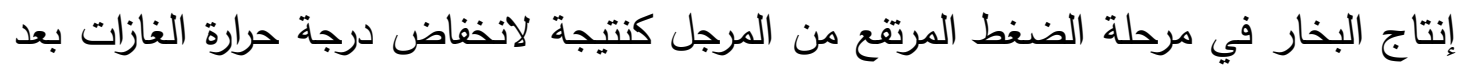

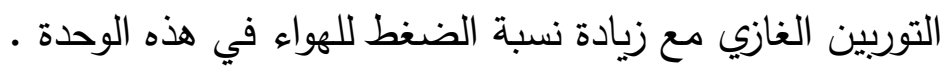


كما ان تأثير الخواص "الثرموديناميكية الأساسية لوحدة التوربين الغازي على مقدار الطاقة

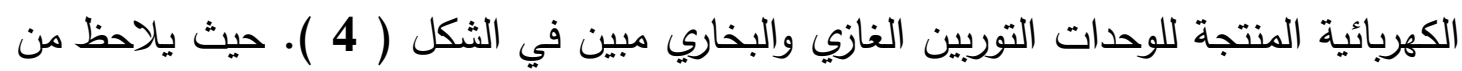

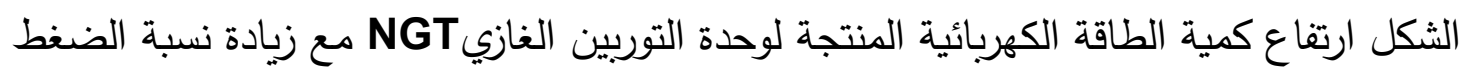
للهواء في هذه الوحدة ـ وذللك بسبب ارتفاع كمية الغازات المطلوبة لإنتاج كمية البخار اللازمة

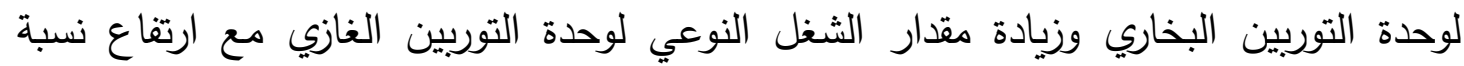

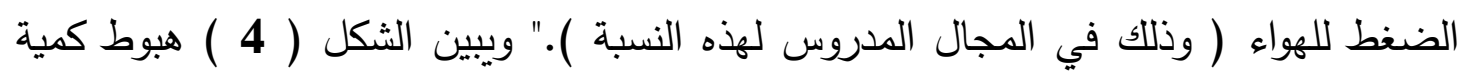
الطاقة الكهربائية المنتجة للوحدة التربينية البخارية NST مع زيادة نسبة الضغط للهواء ـ والسبب في ذلك يعود إلى انخفاض كمية البخار المنتجة في مرحلة الضغط المرتفع من المرجل ( DSB1 ( DS1 )

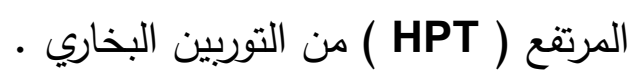

وان تأثير درجة الحرارة الابتدائية للغازات على مقدار الطاقة الكهربائية المنتجة للمركز الكهروحراري المزدوج مبين في الثكل ( 4 ). حيث يلاحظ من الثكل انخفاض مقدار الطاقة

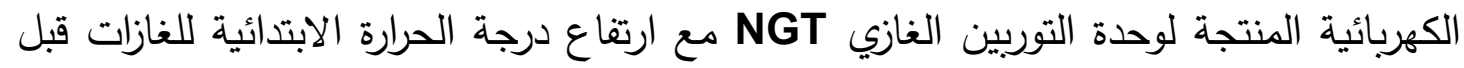
التوربين الغازي • والسبب في ذلك يرجع إلى ارتفاع درجة حرارة الغازات بعد التربينة الغازية . ومن ثم انخفاض كمية الغازات المطلوبة لإنتاج كمية البخار اللازمة للوحدة التربينية البخارية

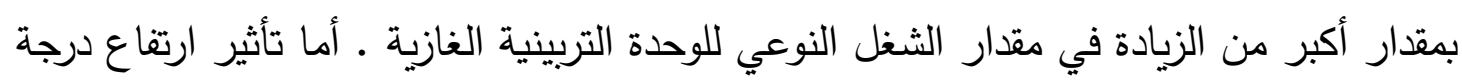

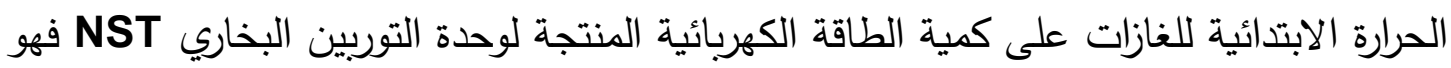

$$
\text { زيادة الطاقة الكهربائية المنتجة لهذه الوحدة " }
$$

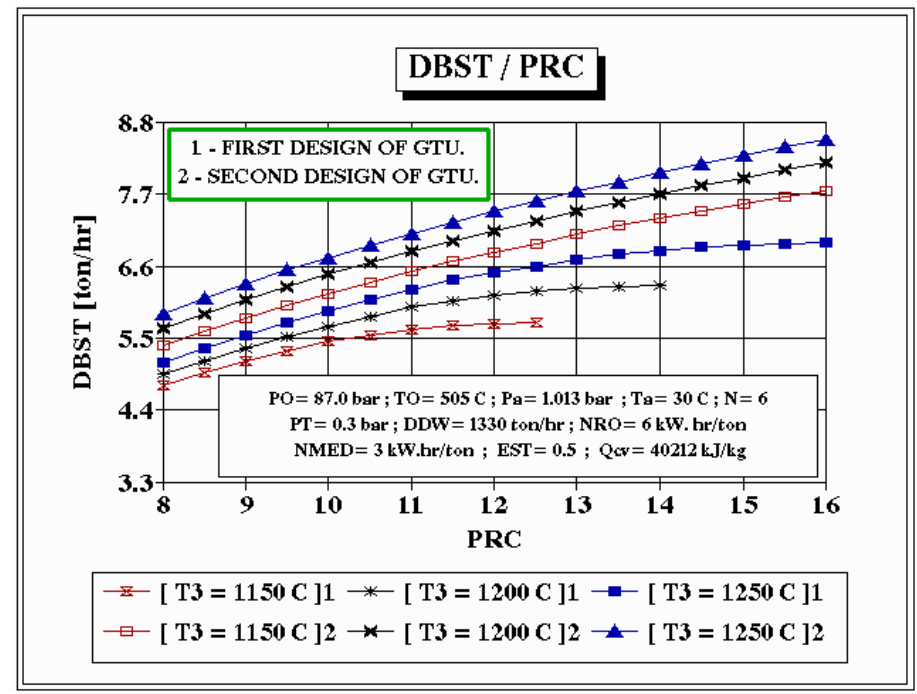

الثكل ( 3 ) يوضح علاقة مقدار التوفير في كمية الوقود المستهكة ( DBST ) مع نسبة

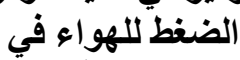

وحدة التوربيني الغازي( PRC ) عند قيم مختلفة لارجة الحرارة الابتائية للغازات ( T3 ). 


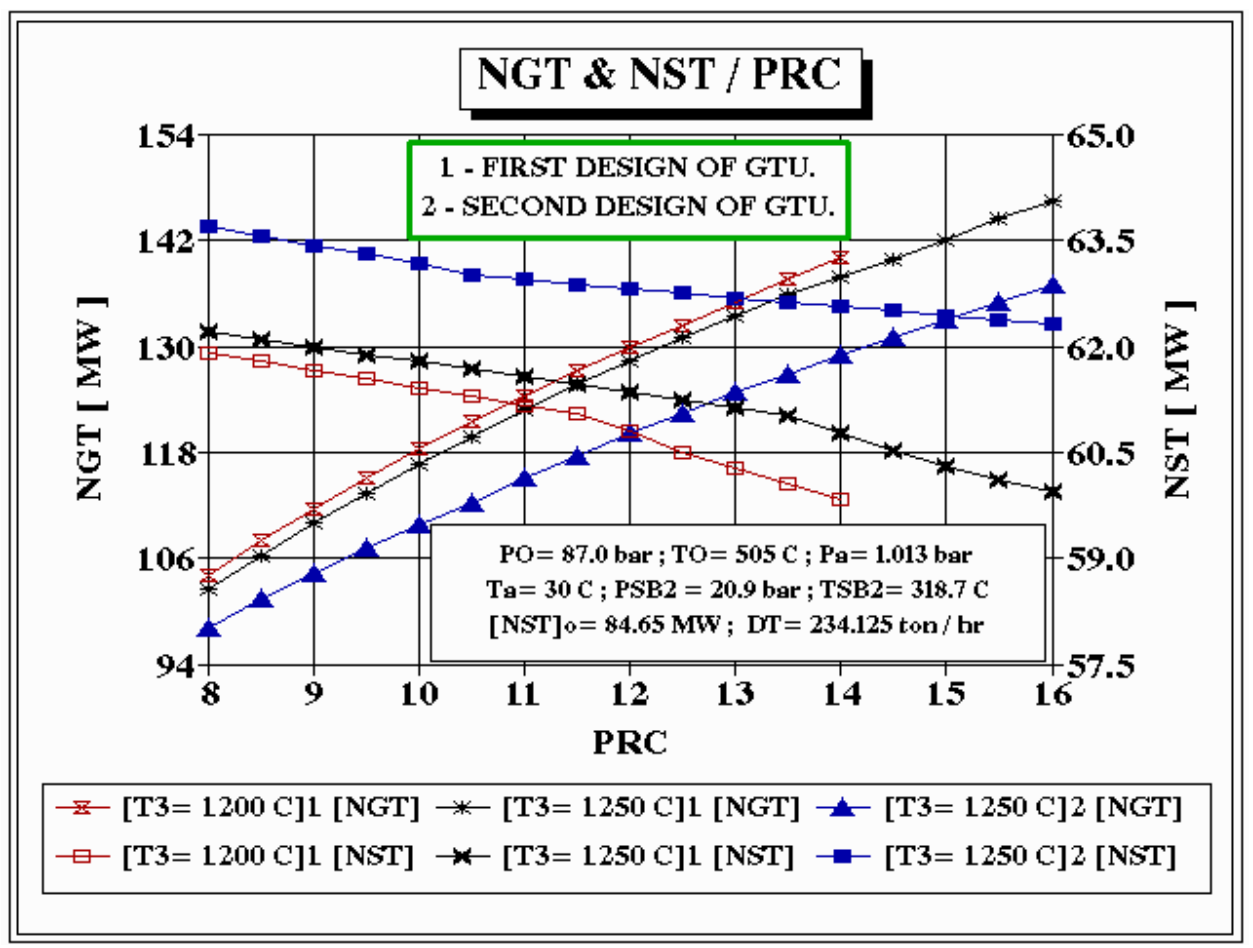

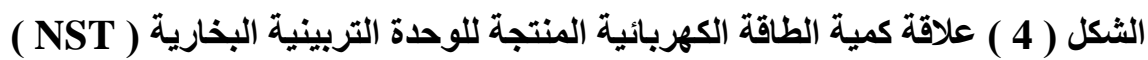
( مع نسبة الضغط للهواء في الوحدة التربينية الغازية ( NGT ) الحرارة الابتدائية للغازات ( T3 ) .

"وذللك بسبب ارتفاع كمية البخار المنتجة في مرحلة الضغط المرتفع من المرجل ( DSB1 ، الشكل ( 5 ) ) • ومن ثم زيادة مقدار الطاقة الكهربائية المنتجة لاسطوانة الضغط المرتفع من التوربين البخاري. وكذلك يبين الشكل ( 4 ) عند ثبوت الخواص الثيرموديناميكية المدروسة لوحدة التوربين الغازي فان استخدام الاحتراق المتتابع في هذه الوحدة يؤدي إلى زيادة كمية الطاقة الكهربائية المنتجة لوحدة التوربين البخاري NST وهبوط كمية الطاقة الكهربائية المنتجة لوحدة التوربين الغازي NGT . ويمكن تفسير ذلك إلى ارتفاع درجة حرارة غازات الاحتراق بعد التوربين

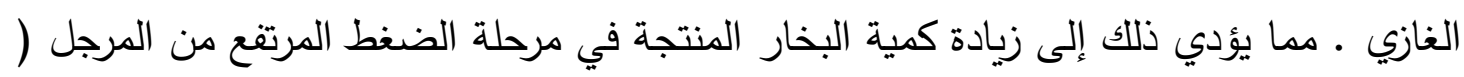
DSB1 ، الثكل ( 5 ()) وانخفاض كمية غازات الاحتراق المطلوبة في المرجل لإنتاج كمية البخار اللزمة لوحدة التوربين البخاري بمقدار أكبر من الزيادة في الشخل النوعي لوحدة التوربين

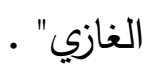




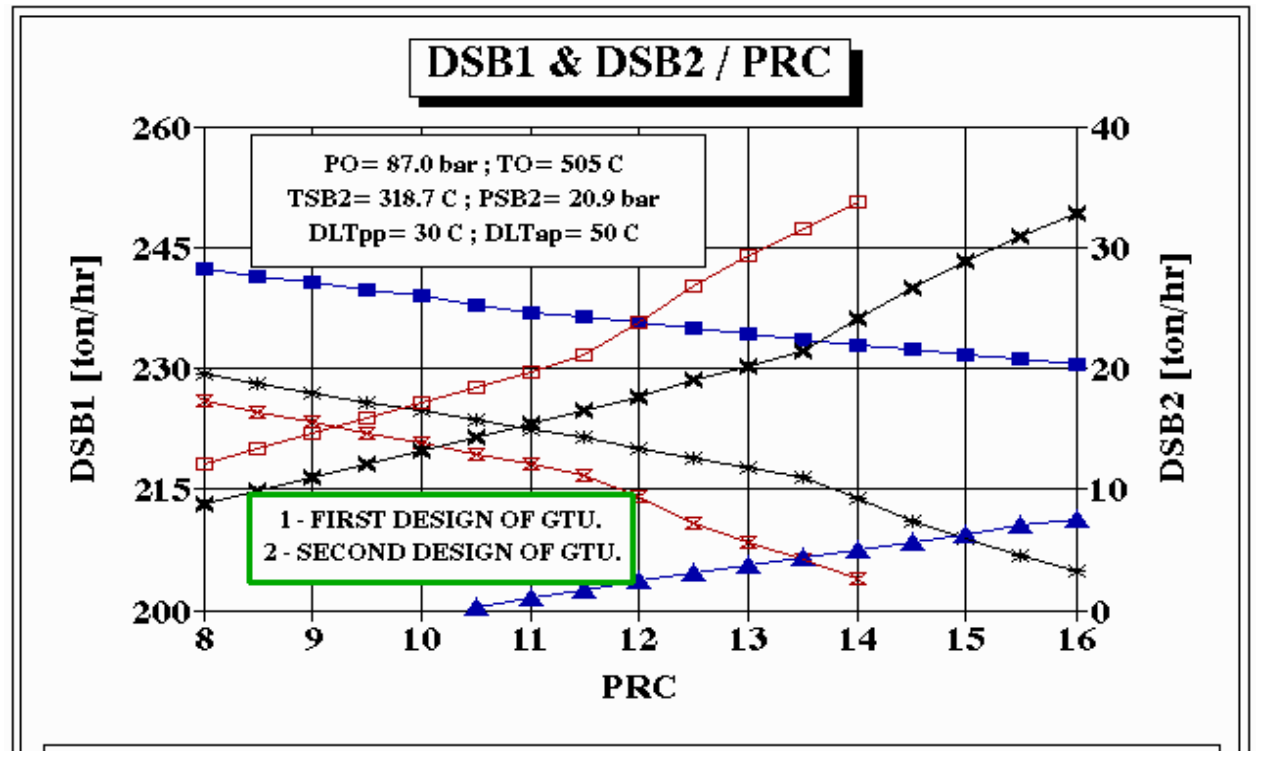

الثكل ( 5 ) علاقة كمية البخار المنتجة في مرحلتي الضغط للمرجل مع نسبة الضغط للهواء الضغ في الوحدة

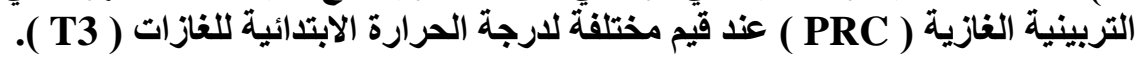

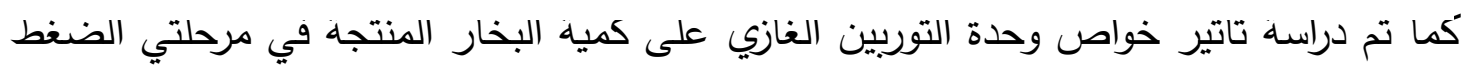
من المرجل ." حيث يلاحظ من الشكل ( 5 ) عند ثبوت نسبة الضغط للهواء وزيادة درجة الحرارة الابتدائية للغازات ارتفاع كمية البخار المنتجة في مرحلة الضغط المرتفع من المرجل DSB1 . وذلك بسبب زيادة كمية الطاقة الحرارية المتاحة لإنتاج البخار في هذه المرحلة نتيجة لارتفاع درجة حرارة الغازات بعد التوربين الغازي وكذلك يلاحظ هبوط كمية البخار المنتجة في مرحلة الضغط المنخفض من المرجل DSB2 مع ارتفاع درجة الحرارة الابتدائية للغازات قبل التوربين الغازي. والسبب في ذلك يمكن تفسيره إلى انخفاض درجة حرارة غازات الاحتراق بعد موفر مرحلة الضغط المرتفع من المرجل نتيجة لزيادة كمية الطاقة الحرارية اللازمة لتسخين مياه التغذية لهذه المرحلة من المرجل ". وعند زيادة نسبة الضغط للهواء وثبوت درجة الحرارة الابتدائية للغازات يلاحظ من الشكل ( 5 ) هبوط كمية البخار المنتجة في مرحلة الضغط المرتفع من المرجل . وذلك بسبب انخفاض كمية الطاقة الحرارية المتاحة لإنتاج البخار في هذه المرحلة ـ أما كمية البخار المنتجة في مرحلة الضغط المنخفض من المرجل فأنها تزداد مع ارتفاع نسبة الضغط للهواء • والسبب في ذلك يعود إلى انخفاض كمية مياه التغذية اللازمة لمرحلة الضغط المرتفع من المرجل • ومن ثم ارتفاع درجة حرارة غازات الاحتراق بعد موفر هذه المرحلة من المرجل . وبالتالي زيادة كمية الطاقة الحرارية المتاحة لإنتاج البخار في مرحلة الضغط المنخفض من

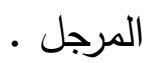

ان تأثير ضغط البخار المجهز "لوحدة التحلية PT وكفاءة المحطة التعويضية EST لإنتاج الطاقة الكهربائية وكذلك معدل استهلاك الطاقة الكهربائية لإنتاج مياه التحلية في وحدة التحلية من نوع التناضح العكسي على مقدار التوفير في كمية الوقود المستهلكة DBST مبين في الشكل ( 6 ). حيث يلاحظ من الثكل هبوط مقدار التوفير في كمية الوقود المستهلكة ( 
(DBST1

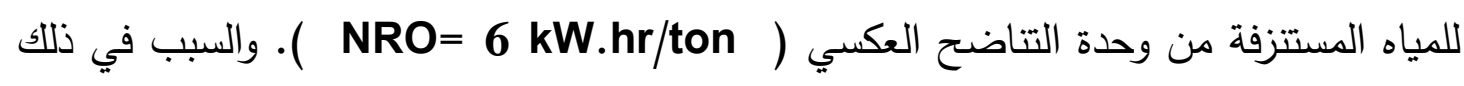

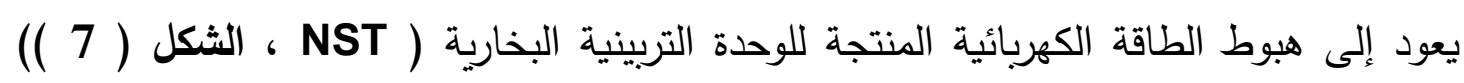

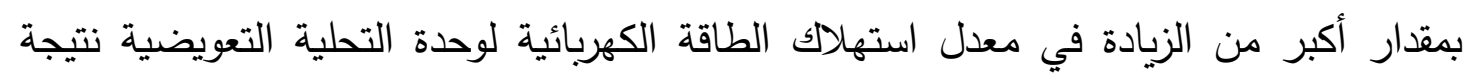

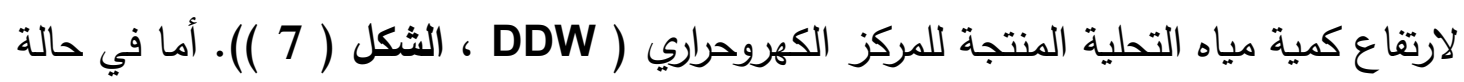
NRO= عدم استرجاع الطاقة الهيدروليكية للمياه المستنزفة من وحدة التحلية ( ( kW.hr/ton

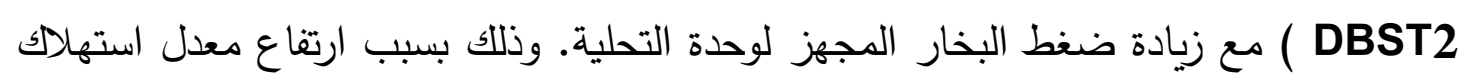

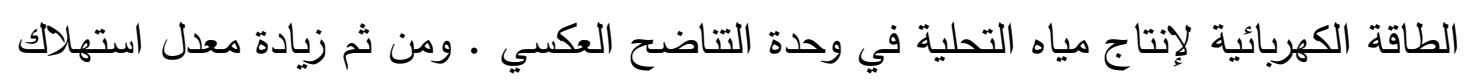

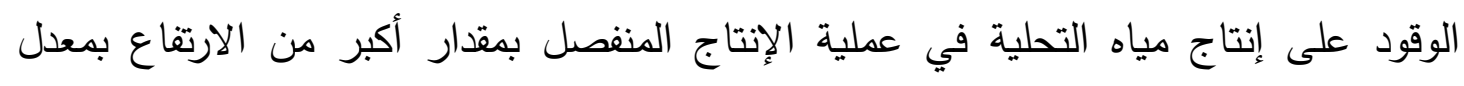

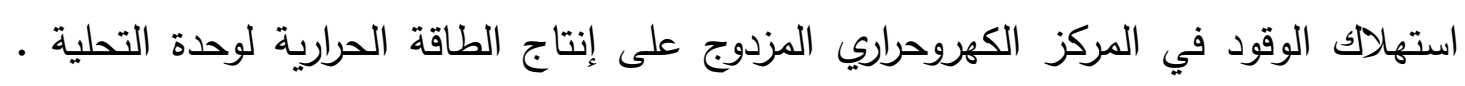

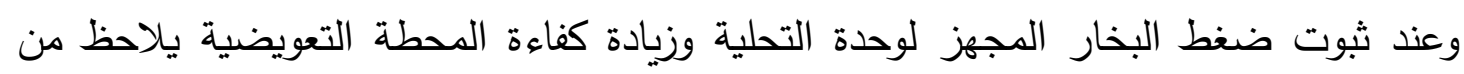

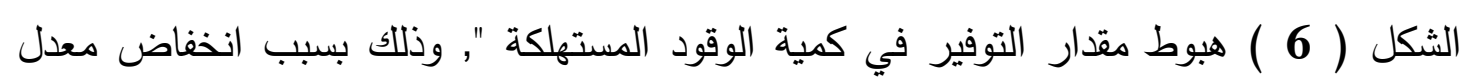
استهلالك الوقود على إنتاج الطاقة الكهربائية في المحطة التعويضية.

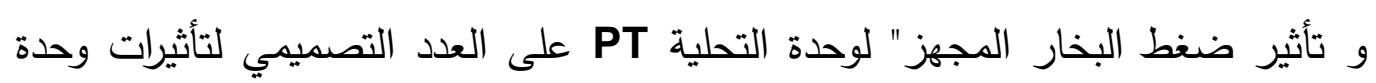

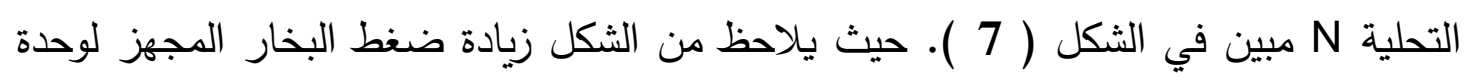

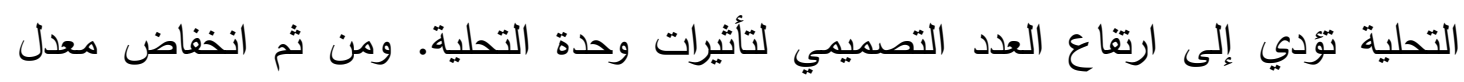

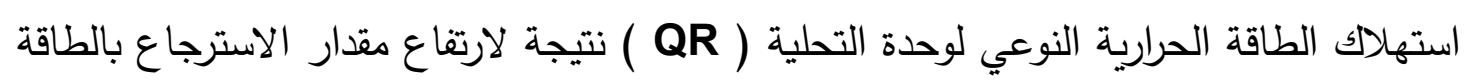
الحرارية لوحدة التحلية. وبالتالي ارتفاع كمية مياه التحلية المنتجة "( DDW ). 


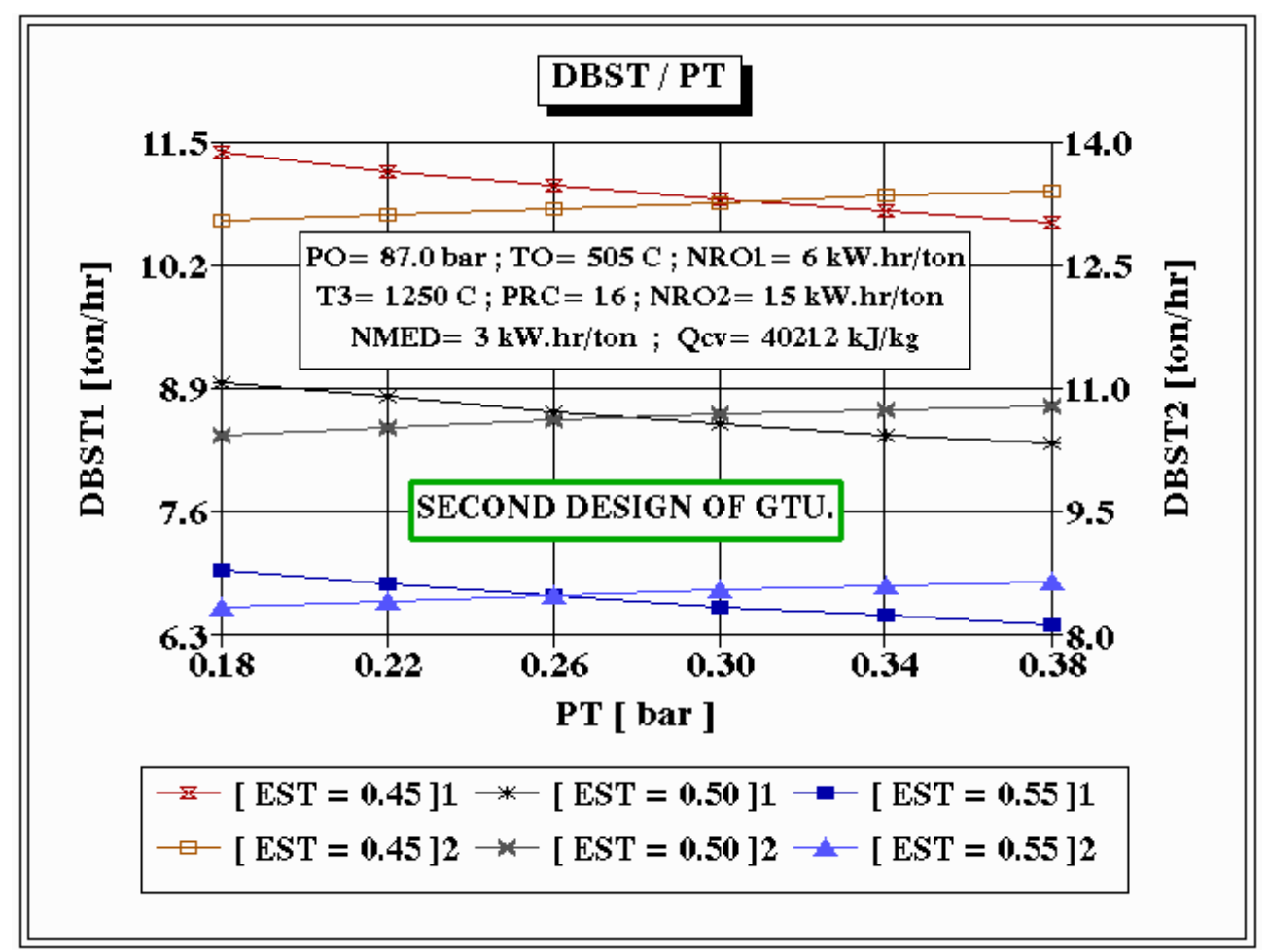

الثكل ( 6 ) علاقة مقدار التوفير في كمية الوقود المستهلكة ( DBST ) مع ضغط البخار المجهز لوحدة التحلية ( PT ( PT ) عند قيم مختلفة لكفاءة المحطة التعويضية ( EST ). الطاقة الحرارية

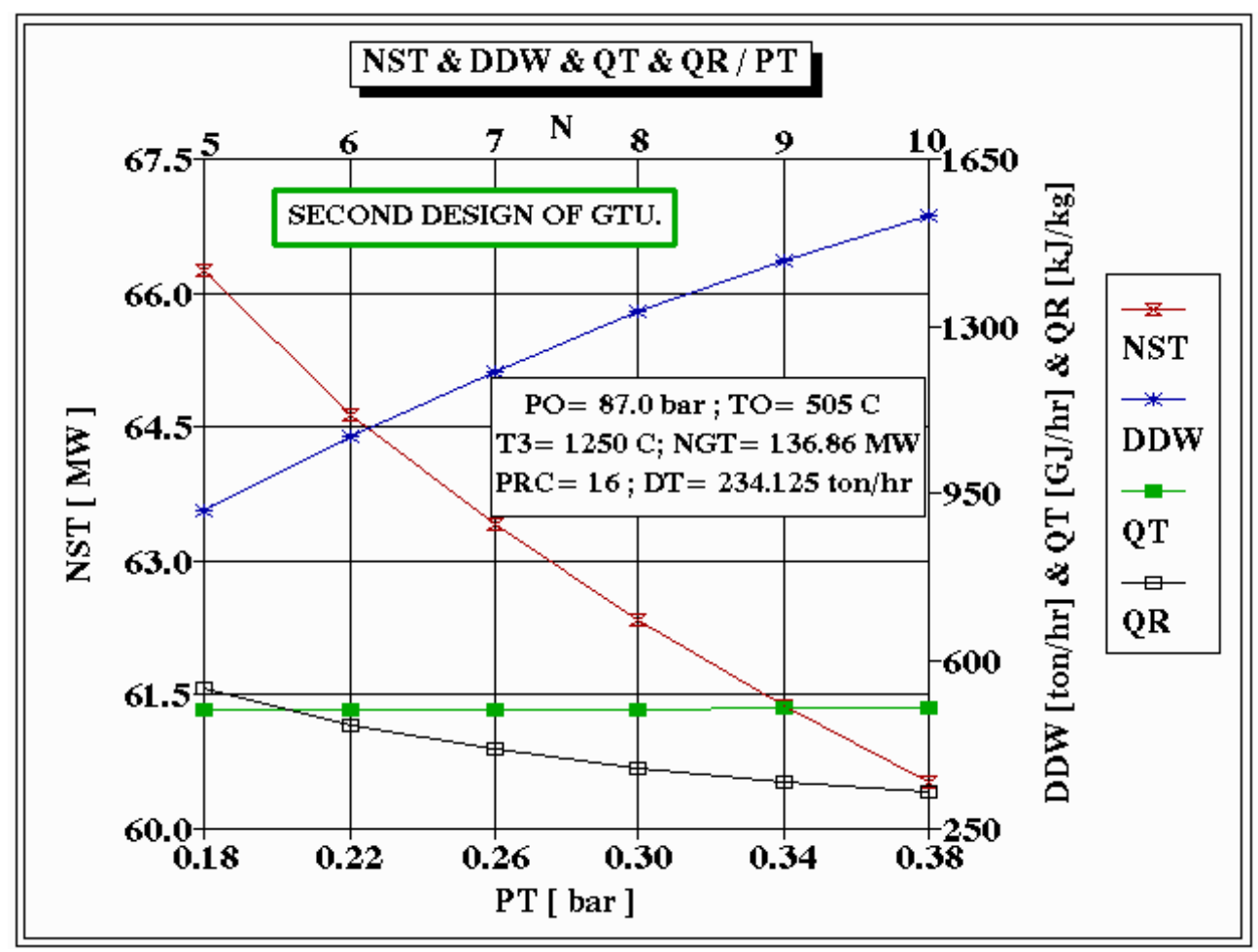

الثكل ( 7 ) علاقة كمية الطاقة الكهبائية المنتجة للوحدة التربينية البخارية ( NST ) ، كمية المجهزة لوحدة التحلية ( QT ) ، معدل استهلاك الطاقة الحرارية النوعي لوحدة التحلية (

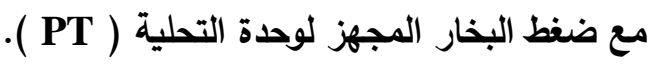


وكذلك يبين الثكل( 7 )" ارتفاع بسيط في كمية الطاقة الحرارية المجزة لوحدة التحلية

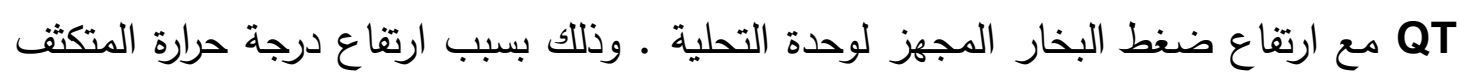

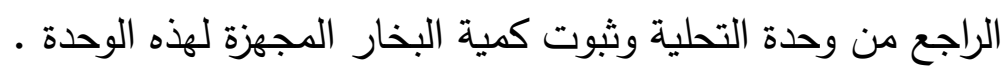

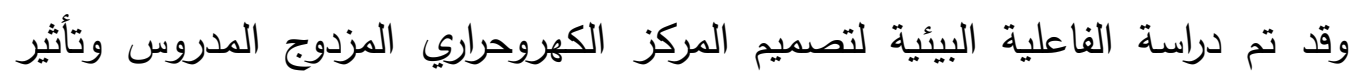

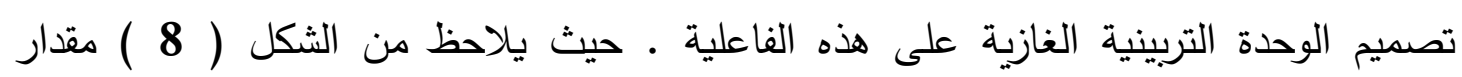

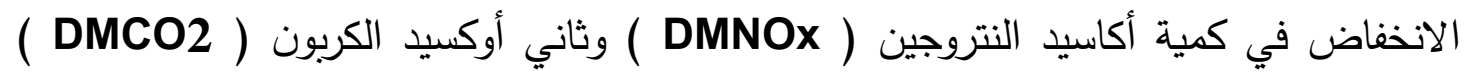

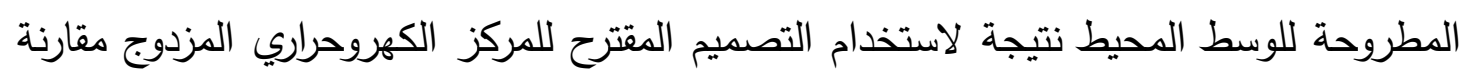

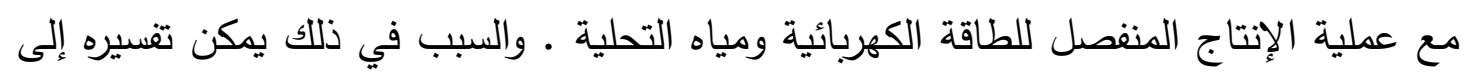
هبوط معدل استهلاك الوقود لإنتاج نوعي الطاقة ( الطاقة الكهربائية والحرارية ) في التصميم

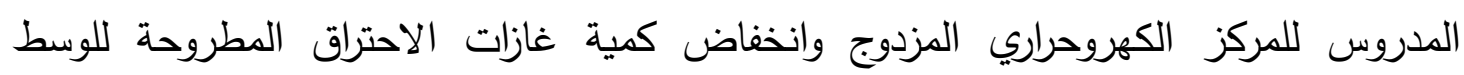

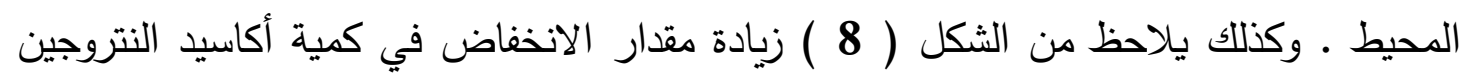

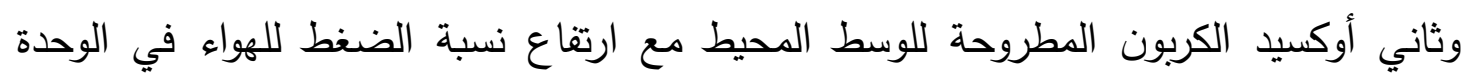

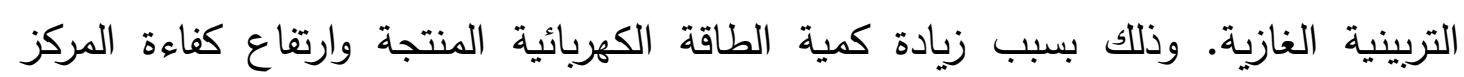

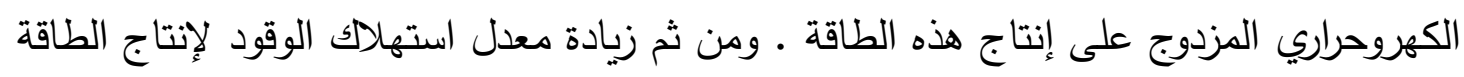

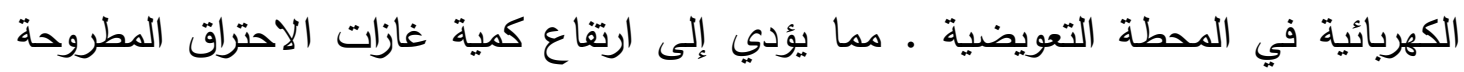
للوسط المحيط في عملية الإنتاج المنفصل للطاقة الكهربائية ومياه التحلية".

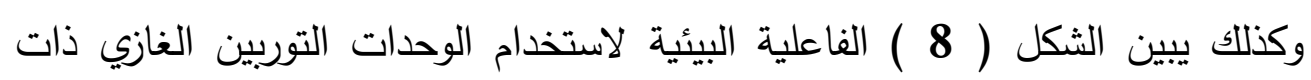

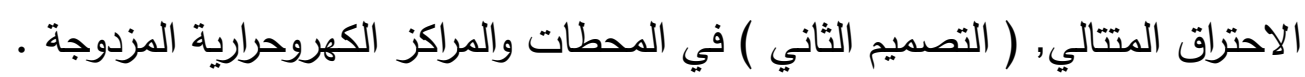

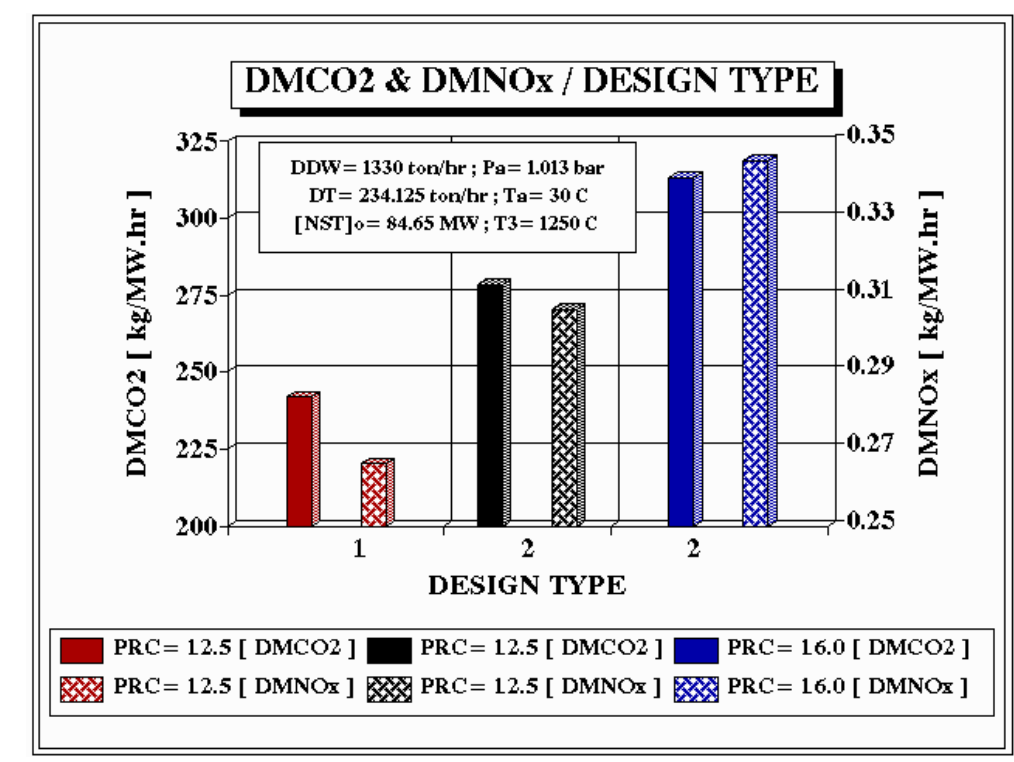

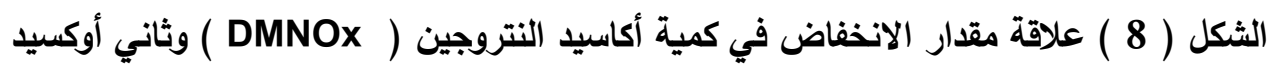

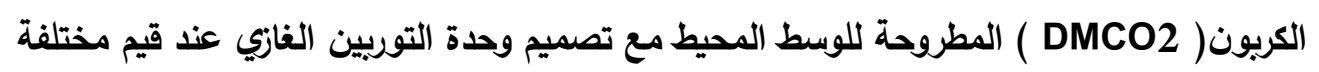
لنسبة الضغط للهواء ( PRC ) في هذه الوحدة . 
حيث" بلغ أدنى مستوى من الزيادة في مقدار الانخفاض في كمية أكاسيد النتروجين وثاني

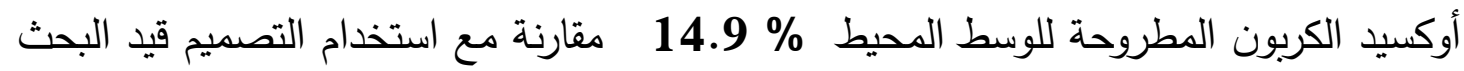

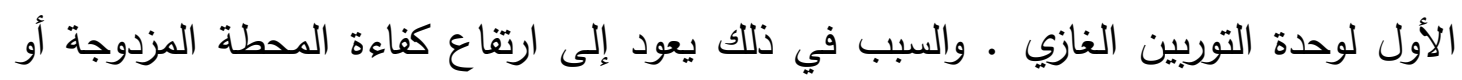

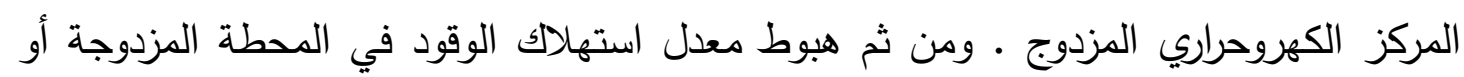
المركز الكهروحراري المزدوج على إنتاج الطاقة الكهربائية ".

\section{1}

ان دراسة اداء التصميم "المقترح للمركز الكهروحراري المزدوج تبين ان :

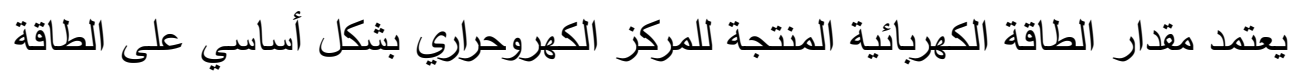
الكهربائية التصميمية لوحدة التوربين البخاري وكذلك على تصميم هذه الوحدة.

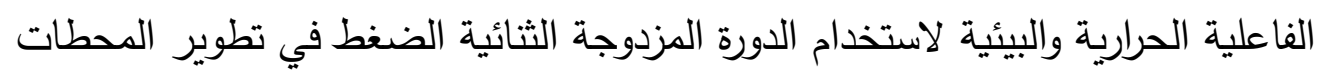

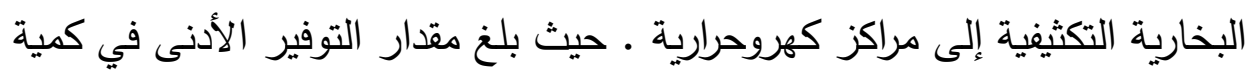

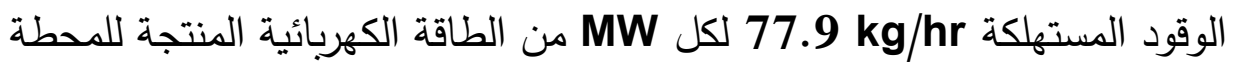
البخارية ـ وطبقا لذلك فان مقدار الانخفاض في كمية أكاسيد النتروجين

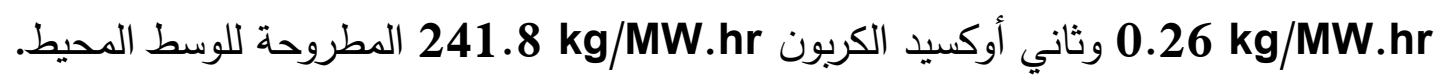
وذلك عندما يكون ضغط البخار المجز لوحدة التحلية 0.3 bar وطبقا لذلك العدد التصميمي

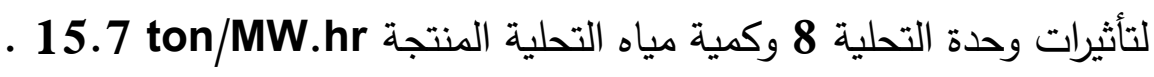
تزداد الفاعلية الحرارية والبيئية للمركز الكهروحراري مع ارتفاع الخواص الثيرموديناميكية

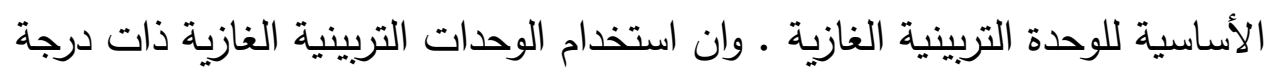

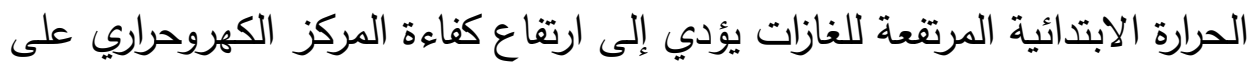

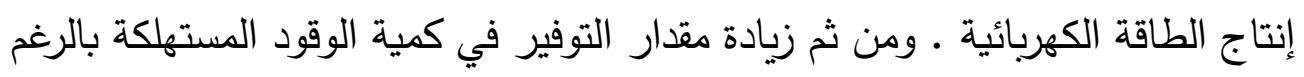
من انخفاض مقدار الزيادة في كمية الطاقة الكهربائية المنتجة للمركز الكهروحراري.

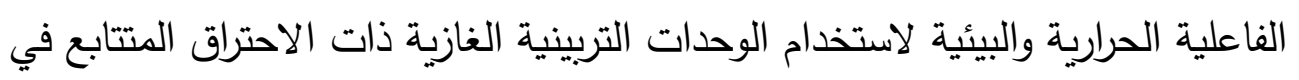

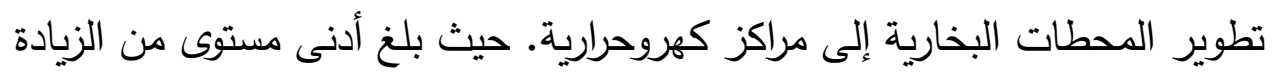

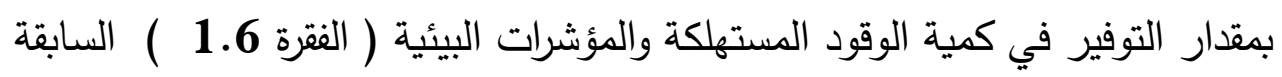
الذكر أعلاه \% 14.9 .

ارتفاع ضغط البخار المجز لوحدة التحلية من 0.38 bar 0 bar 0 baؤدي

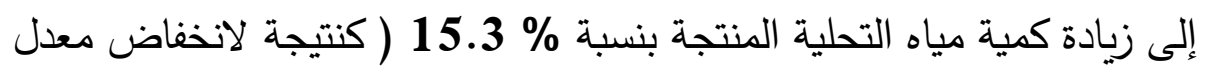
استهلاك الطاقة الحرارية النوعي لوحدة التحلية ) وكذلك هبوط الطاهية الكاة الكهربائية المنتجة لوحدة التوربين البخاري بمعدل \% 2.9 ". 
يمكن " إجراء دراسة جدوى حرارية لبيان فعالية المواصفات التصميمية والخواص الثرموديناميكية المثالية للتصميم المقترح التي تعطي أقصى فاعلية اقتصادية ممكنة مع الأخذ بعين الاعتبار مقدار التغير في كلفة وحدة التوربين الغازي والمرجل المخصص لاستغلال الطاقة الحرارية لغازات العادم مع الخواص والمواصفات التصميمية لهذه الوحدة ـ وذلك لتأثير هذه الخواص والمواصفات على كمية البخار المنتجة في مرحلتي الضغط من المرجل ـ وون ثم المساحات السطحية للتبادل الحراري المطلوبة لإنتاج هذه الكميات من البخار ". كما يمكن تنفيذ مثل هكذا مشروع لحل ازمة البصرة والمناطق الجنوبية بشكل عام في توفير مياة الشرب وكذلك توليد الطاقة الكهربائية بكلفة معقولة ومواصفات جيدة اذا ما تم تطبيق هذا البحث بشكل عملي وادارة رصينة لتحقيق التوافق بين الجانبين النظري والعملي وبشكل مدروس • 
2.3 الرموز المستخدمة مع الجدول والريسوم التوضيحية:

\begin{tabular}{|c|c|c|}
\hline معناه & الرمز & التسلسل \\
\hline المكثف وخزان نزع الهواء & D, C & 1 \\
\hline كمية مياه التحلية المنتجة للمركز الكهروحراي المزدوج & DDW & 2 \\
\hline فلمبخرت فرجات المرارة الأصغر على الطرف الساخن لمحمصات البخار والطرف البارد & DLTpp, DLTap & 3 \\
\hline كمية وضغط البخار المجهز لوحدة التحلية على الترتيب & PT, DT & 4 \\
\hline كفاءة المحطة المزدوجة التعويضية لإنتاج الطاقة الكهربائية . & EST & 5 \\
\hline مضخة مياه التظذية والمتكثف الأساسي على الترتيب & CP, FP & 6 \\
\hline خزان التمدد للمياه المستنزفة من اسطوانتي المرجل & FV & 7 \\
\hline مسخن مياه التغذية أو المتكثف الاساسي رقم (i ) & FWHi & 8 \\
\hline مرجل استغلال الطاقة الحرارية لغازات العادم الخارجة من الوحدة التربينية الغازية & HRSB & 9 \\
\hline اسطوانة الضغط المنخفض والمتوسط والمرتفع للتربينة البخارية على الترتيب & HPT , IPT , LPT & 10 \\
\hline وحدة التحلية التبخيرية المتعددة التأثير & MED & 11 \\
\hline النوعي العدد التصيمي لتأثيرات وحدة التحلية التبخيرية ومعل استهلاك الطاقة الكهربائية & NMED, $\mathbf{N}$ & 12 \\
\hline معدل استهلاك الطاقة الكهربائية النوعي لوحدة التحلية من نوع التناضح العكسي & NRO & 13 \\
\hline 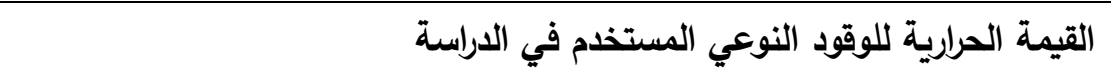 & Qev & 14 \\
\hline مسخن المياه التعويضية للمركز الكهروحراري المزلوج & RFWH & 15 \\
\hline المرجل البخاري & SB & 16 \\
\hline درجة الحرارة والضغط على الترتيب & $\mathbf{P}, \mathbf{T}$ & 17 \\
\hline درجة الحرارة والضغط الابتدائي للبخار قبل التوربين البخاري على الترتيب & Po, To & 18 \\
\hline درجة الحرارة والضغط للهواء في الوسط المحيط على الترتيب & $\mathbf{P a}, \mathbf{T a}$ & 19 \\
\hline ـ درجة حرارة وضغط البخار المنتج في المرحلة الثانية من المرجل على الترتيب & PSB2, TSB2 & 20 \\
\hline الطاقة الكهربائية المنتجة في حالة التصميم الأساسي للمحطة البخارية & [ NST ]o & 21 \\
\hline
\end{tabular}


1. GHASSAN EJJEH (2001) Desalination, A Reliable Source of New Water / IDA World Congress on Desalination and Water Reuse. ( Internet Communication )

2. LEON AWERBUCH ( 2001 ) Desalination and Power Development in the New Millennium / Sustainable Development International. ( Internet Communication ).

3. Cogeneration Plant with Desalination ( 1995 ) CMI, Energy Division, Avenue Greiner - 1 ,B - 4100 , Seraing, Belgium. MIRO R. SUSTA \& PETER LUBY ( 1997 )

4. Combined Cycle Power Plant Efficiency: a prognostic extrapolation / Modern Power Systems Journal, pp. 21: 24, April, 1997.

5. VINCENT BAUJAT ( 2000 ) Comparison of Multiple Effect and Multistage Flash Desalination Processes for Power and Water Combined Plants / The International Conference and Exposition on Energy and Water desalination , IEF / ISESCO , 20 : 21 June, Tripoli - LIBYA .

6. HUSSAIN A. A. (1998) The Economical Effectiveness of Using The Modern Technology To Solve Energy and Environmental Problems / The Third Workshop on Energy \& The Environment, IEF, 20: 21 October, Tripoli LIBYA.

7. GOFFIN J.P. (2001) Verbrande Brug reborn as Vilvoorde Combined Cycle Plant / Modern Power Systems Journal, pp. 19: 21, January, 2001.

8. AMINOV R.Z. \& KLEBALEN U.M. (1989) Cogeneration Steam Power Plants / Moscow, Vish. Shcola, $256 \mathrm{pp}$.

9. ARSENYEV I.V. \& TYRYSHKIN V.G. (1989) Gas Turbine Plants / Leningrad, Mashinostroine, $543 \mathrm{pp}$.

10. ARDEN B.W. (1995) Power Plant Topping Cycle Repowering / Energy Engineering (USA), Vol. 92, No. 5, pp. 49: 71.

11. VOINOV A.P. \& KUPERMAN L.E. (1989) Heat Recovery Steam Boilers / Moscow, Energia, 272 pp.

12. JERNQVIST A. \& JERNQVIST M. ( 1999 )Similation of Thermal Desalination Processes / Desalination and The Envirnment Conference , Las Palmas , Gran Canaria , November $9: 12,1999$.

13. LUTHI ( 1994 )The ABB GT24/26 Gas Turbine Family with Sequential Combustion /

PowerGen Europe Conference, Vol. 9, May 1994, Koln, Germany. 